\title{
APLICAÇÃO DA ANÁLISE DE CONTINGENCIAS NO MANEJO DA DIFICULDADE ALIMENTAR NA INFÂNCIA.
}

\section{Pôster}

Autores deste trabalho:

Rafael Baptista de Melo: Centro de Dificuldades Alimentares - Instituto PENSI

Raquel Ricci: Centro de Dificuldades Alimentares - Instituto PENSI

Rachel HV Machado: Centro de Dificuldades Alimentares - Instituto PENSI

Maria Julia Russo de Carvalho: Centro de Dificuldades Alimentares - Instituto PENSI

Claudia de Cássia Ramos: Centro de Dificuldades Alimentares - Instituto PENSI

Priscila Maximino: Centro de Dificuldades Alimentares - Instituto PENSI

Mauro Fisberg : Centro de Dificuldades Alimentares - Instituto PENSI

Área do Trabalho: Nutrição

Data da submissão: $26 / 07 / 2018$ às $16: 28$

\section{Justificativa}

A Dificuldade Alimentar (DA) é altamente influenciada pela interação da criança com seu ambiente. Por isso, podem ser utilizadas técnicas comportamentais para reduzir a recusa alimentar. Uma das mais utilizadas é a análise funcional, que investiga a relação entre eventos ambientais e comportamentos por meio da tríplice contingência (relação entre estímulo antecedente, resposta e consequência).

\section{Objetivo(s)}

Demonstrar a aplicação da análise de contingências na área de DA.

\section{Método(s)}

Estudo descritivo observacional com análise de vídeo gerado em consulta em ambulatório especializado em DA, com uma criança do sexo feminino de 3 anos, de desenvolvimento típico, com recusa alimentar. A partir de padrão de comportamentos a serem observados de forma sistemática, registrou-se os comportamentos (resposta) apresentados pela criança frente um evento (antecedente), e quais consequências esta resposta gerou. A pesquisa foi aprovada por comitê de ética, sob-registro CAAE 32939314.0.0000.5567.

\section{Resultado(s)}

Como Antecedentes, foram identificadas no vídeo 6 ofertas de alimento e 2 sustentações da oferta (segurar e manter o talher na frente da criança). A resposta da criança frente ao antecedente foi com vocalizações negativas ou comportamentos de fuga (mudar de assunto, pedir para fazer outra atividade), recusa de sentar-se à mesa, empurrar o alimento/utensilio/mão do cuidador, bloquear o acesso a sua própria boca ou recusa com a cabeça e com o corpo. As consequências para tais respostas foram principalmente o afastamento da oferta do alimento, substituições da oferta, permissão para a criança sair da posição ou encerramento da alimentação. 


\section{Conclusão(ões)}

Os resultados da observação sugerem que as consequências podem sustentar ou moldar a resposta da criança e manter a recusa. Assim, a intervenção no comportamento final do cuidador se faz necessária para modular a resposta da criança. Este tipo de análise é útil no desenvolvimento de programas de diagnósticos e de tratamento da DA. 